\title{
Manifiesto Desarme para el desarrollo humano y sostenible
}

Recibido: 21.06.2016 / Aprobado: 22.06.2016

El presente manifiesto es una iniciativa de International Peace Bureau (Ginebra), preparada de cara a la celebración, por parte de la Asamblea General del Foro de Alto Nivel de las Naciones Unidas de Cultura de Pazy No Violencia, a realizarse el próximo mes de septiembre (2016).

"Com-partir, es la única solución para evitar las gravísimas desigualdades sociales y asimetrías de todo orden a que ha conducido el neoliberalismo globalizador.

Insisto -porque es una referencia esencial en mi comportamiento cotidiano- que es moralmente inaceptable que cada día mueran de hambre más de 20.000 personas al tiempo que se invierten en gastos militares y armamento 3.000 millones de dólares. Bastaría con una reducción razonable de estas ingentes y desproporcionadas cifras para que pudieran incrementarse rápida y sustancialmente las ayudas al desarrollo endógeno, sostenible y humano, en todo el mundo; se atendiera el crucial legado intergeneracional del medio ambiente, asegurando que no tenga

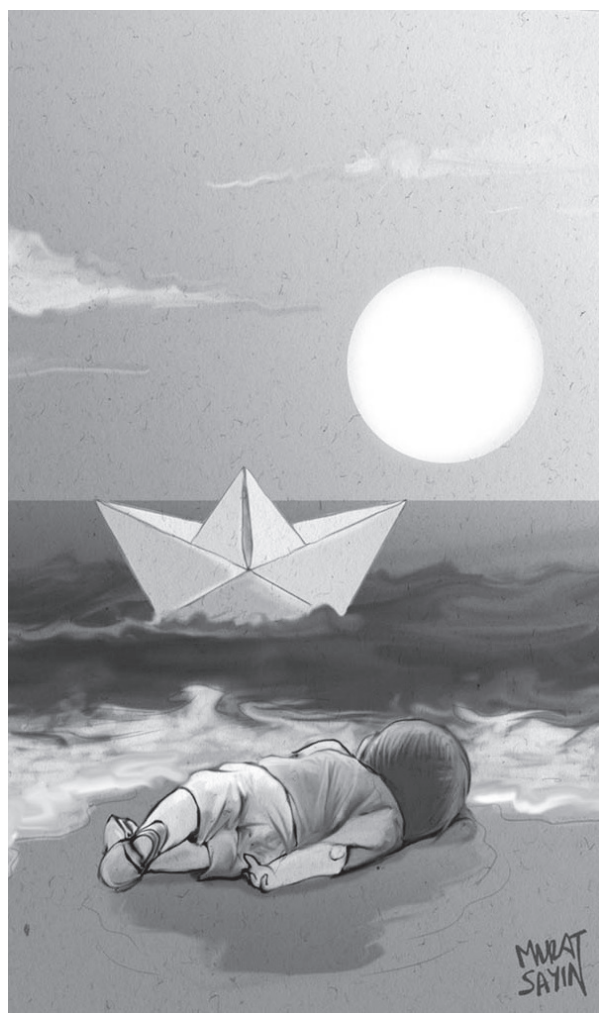

comienzo" que preconiza la Carta de la Tierra.

Todos los seres humanos iguales en dignidad. Cada ser humano único capaz de crear, de diseñar su propio futuro en un proceso de educación permanente, de tal modo que todos sean "libres y responsables", como define magistralmente la UNESCO a los "educados", actuando siempre en virtud de las propias reflexiones y nunca más al dictado de nadie. Con el fanatismo y dogmatismo, tolerancia cero.

Es tiempo de acción, porque pueden alcanzarse puntos de no retorno. Ya disponemos de múltiples diagnósticos. Ahora corresponde aplicar sin demora tratamientos adecuados. Es apremiante la lugar el deterioro irreversible de la habitabilidad de la Tierra; la cooperación internacional permitiría la puesta en práctica de las grandes prioridades de las Naciones Unidas (alimentación, agua, salud, ecología, educación, paz...); y, sobre todo, se haría posible el "nuevo refundación del Sistema de Naciones Unidas después de los ineficientes e infaustos grupos plutocráticos (G-7, G-8, G-20), que el neoliberalismo estableció en la década de los ochenta. ¿Cómo pudo pretenderse -y aceptarse- que 6, 7, 8... 20 países guíen los destinos de 193? Y, sobre todo, 
deben re-ponerse los "principios democráticos", que con tanta precisión y clarividencia establece la Constitución de la UNESCO, en donde el Partido Republicano de los Estados Unidos, en sus ambiciones hegemónicas situó las leyes mercantiles.

Ahora ya es posible, en la era digital, que "Nosotros, los pueblos...", silentes y obedientes desde tiempo inmemorial puedan levantar la voz y participar activamente. Ahora, con la mujer progresivamente incorporada al proceso de toma de decisiones, ya es posible el imposible sueño de emancipación de la humanidad hasta hace bien poco años.

Ahora ya podemos imaginar en el ciberespacio grandes clamores populares para los cambios radicales que se requieren con apremio. No tendrá lugar, por fortuna, la guerra de las galaxias en el espacio sideral sino que será en el espacio "digital" donde se originará la nueva paz, la formidable transición desde la fuerza a la palabra, desde una cultura de imposición, dominio y violencia a una cultura de encuentro, diálogo, conciliación y paz.

¿Cómo puede Europa, la gran emigrante, rechazar ahora a los inmigrantes? ¿Cómo puede poner obstáculos a su acceso en lugar de intensificar la ayuda al desarrollo para una vida digna en sus lugares de origen? ¿Por qué no completa rápidamente su edificio constitucional con una unión política y económica? ¿Cómo puede aceptarse que la pretendida Europa-faro se haya detenido y circunscrito a una unión monetaria? ¿Por qué Europa sigue las pautas dictadas por el Partido Republicano norteamericano, cuando el propio Presidente Obama, para el bien de su país, las apartó cómo correspondía?

Debo advertir -jotra vez!- que si no hay evolución habrá revolución y que la diferencia entre estas dos palabras es la " $r$ " de responsabilidad. Dejemos de seguir a los irresponsables y, con urgencia, facilitemos la transición de una economía basada en la especulación, la deslocalización productiva y la guerra a una economía de desarrollo sostenible y humano. De una cultura de guerra a una cultura de paz, liderada por un a multilateralismo democrático y eficiente.

La mejor solución -aunque tengamos que sobreponernos a la inmensa inercia de quienes se aferran al perverso adagio de "si quieres la paz, prepara la guerra" es el desarme (incluido, desde luego, el nuclear), aplicando una parte razonable de los colosales medios dedicados a la seguridad para el desarrollo de todos los pueblos, de tal modo que se haga realidad la igual dignidad y calidad de vida en todos ellos.

Desarme para el desarrollo: así de sencillo. Para ello son necesarias unas Naciones Unidas refundadas con urgencia. La solución existe. Falta el coraje y liderazgo para aplicarla". La acción inmediata es una exigencia de nuestras responsabilidades intergeneracionales.

Sigamos la iniciativa del International Peace Bureau sobre "desarme para el desarrollo" y elevemos en el ciberespacio innumerables voces de justicia y de paz.

¡Seamos "Nosotros, los pueblos..." los que, por fin, tomemos en nuestras manos las riendas del destino común".

\section{Firmantes:}

Federico Mayor Zaragoza - Presidente de la Fundación Cultura de Paz

Antonio Papisca - Emeritus, University of Padua - UNESCO Chair Human Rights, Democracy and Peace University Centre for Human Rights, Padova.

Hartmut Quehl - Presidente del Consorcio Internacional de Investigaciones sobre la Violencia (ICRoV).

Colin Archer - Secretary General International Peace Bureau, Geneve.

Heitor Gurgulino - World University Consortium; Secretary General, The International Association of University Presidents, Brazil.

Roberto Savio - Fundador y Presidente de IPSInternational Press Service, Roma.

Pierre Sané -Director Adjunto para Ciencias Sociales y Humanas de la Unesco. Fue Secretario General de Amnistía Internacional (1992-2001).

Ernesto Samper - Ex Presidente de Colombia. Rigoberta Menchú Tum - Premio Nobel de la Paz 1992, Guatemala.

- Miguel d'Escoto Brockmann - Presidente de la Asamblea General de las Naciones Unidas (2008-2009).

Denis Torres - Director - Instituto Martin Luther King - Managua - Nicaragua. 